\title{
La carrera administrativa en la función pública local: promoción y movilidad
}

\author{
José Carlos Laguna de Paz \\ Catedrático de Derecho Administrativo (acr.) \\ Universidad de Valladolid
}

Sumario: I. SU RELEVANCIA. - II. DIFICULTADES Y SOLUCIONES A LA MEDIDA EN EL ÁMBITO LOCAL. - III. CARRERA PROFESIONAL DENTRO DE LA MISMA ADMINISTRACIÓN. A. Carrera vertical: promoción profesional a través de la provisión de puestos de trabajo. B. Carrera horizontal: promoción profesional sin cambiar de puesto de trabajo. C. Promoción interna. - IV. MOVILIDAD INTERADMINISTRATIVA. A. Provisión de puestos de trabajo por funcionarios con habilitación estatal o autonómica. B. Flexibilización del sistema: movilidad voluntaria de los restantes funcionarios locales.

\section{SU RELEVANCIA}

1. La carrera administrativa es un aspecto relevante del régimen de la función pública, ya que - como la piedra lanzada al estanque - constituye el necesario elemento dinamizador de un sistema caracterizado por la estabilidad en el empleo ${ }^{1}$.

El derecho de los funcionarios de carrera a la inamovilidad ${ }^{2}$ no es un privilegio corporativo, sino la más importante garantía de su imparcialidad ${ }^{3}$. La existencia de una función pública profesionalizada e independiente constituye un verdadero pilar en la vertebración institucional del Estado. No solo es garantía de continuidad en la prestación de los servicios públicos - que no pueden pararse, ni reinventarse con cada proceso electoral (spoil system) - , sino que contribuye también a frenar los posibles excesos de los políticos que estrenan el cargo, siempre tentados a cabalgar a lomos del tigre del poder. Las ventajas del sistema — de hecho - han acabado también siendo ampliamente reconocidas por los países anglosajones, cuyos presupuestos ideológicos liberales les hicieron más reacios a aceptar un funcionariado permanente ${ }^{4}$.

\footnotetext{
1 El presente texto recoge la intervención de su autor en la Jornada «La Función Pública y su Estatuto», organizada por la Federación Regional de Municipios y Provincias de Castilla y León y celebrada en Valladolid, en la sede de las Cortes de Castilla y León, el 12 de diciembre de 2008.

2 En realidad, los funcionarios tienen derecho al cargo, es decir, a no perder la condición de funcionario, salvo sanción (art. 141 TrRL). En cambio, solo tienen un derecho debilitado al puesto de trabajo, que puede ceder ante las necesidades del servicio. SosA WAGNER, F., Manual de Derecho Local, 9. ${ }^{\text {a }}$ edic., ThomsonAranzadi, Pamplona, 2005, págs. 188-189.

3 EM de la Ley 7/2007, de 12.4, del Estatuto Básico del Empleado Público (EBEP).

4 Parada VÁzQueZ, R., Derecho Administrativo, vol. II, 20. a edic., Marcial Pons, Madrid, 2008, págs. 359 y ss.
} 
Ahora bien, garantizada la estabilidad, es también preciso asegurar que - a lo largo de su vida profesional - los servidores públicos realizan sus funciones con la mayor cualificación y perfección posible. Inevitablemente, en parte, ello se conseguirá con el establecimiento de los controles que en cada caso parezcan necesarios. Sin embargo - si se permite el símil-, en general, la zanahoria conseguirá mejores resultados que el palo. La singularidad de la Administración - dirigida por políticos ${ }^{5}$ y pagada por los ciudadanos - hace que los controles de eficiencia que pueden ejercerse sobre la actividad de los funcionarios tengan una virtualidad relativa.

No hay que olvidar que los presupuestos sobre los que se asienta la Administración pública difieren radicalmente de los que animan el funcionamiento de las empresas privadas, sujetas al control implacable del mercado. La tensión de la competencia se traslada de manera natural a toda la estructura empresarial privada, cuya supervivencia es preciso ganarse a diario. Esto no tiene nada que ver con la sosegada atmósfera de los despachos administrativos, desde los que hay que ejercer una tarea equilibrada e imparcial de eficaz servicio al interés general. De la misma forma que el monopolio distorsiona el papel de la iniciativa empresarial, la «huida al mercado» perjudica la función administrativa. Esto explica que las herramientas que son útiles en el ámbito privado pueden ser contraproducentes en el mundo público. Además, siempre hay que estar alerta frente a una posible mediatización política de la función pública, aunque venga envuelta en las más sofisticadas técnicas de gestión de personal y evaluación de rendimientos.

De ahí que la promoción profesional, el estímulo positivo, seguramente, sea el mejor sistema para que los funcionarios realicen sus funciones en las mejores condiciones posibles. En algunos casos, con ello, se conseguirá también retener en la Administración pública a funcionarios cualificados y experimentados, para los que el salto al mundo privado puede resultar una tentación permanente. Naturalmente, la condición para ello es que la promoción profesional se base en criterios objetivos y transparentes, ya que - en caso contrario - la progresión arbitraria solo puede conducir a la ineficiencia de unos y al desánimo de los más.

2. La importancia de la carrera administrativa se refleja en la EM de la Ley 7/2007, que la vincula a la calidad de la Administración y al adecuado cumplimiento de sus funciones: «El sistema de empleo público que permite afrontar estos retos es aquel que hace posible atraer los profesionales que la Administración necesita, que estimula a los empleados para el cumplimiento eficiente de sus funciones y responsabilidades, les proporciona la formación adecuada y les brinda suficientes oportunidades de promoción profesional, al tiempo que facilita una gestión racional y objetiva, ágil y flexible del personal (...)».

5 Martínez LóPeZ-MuÑIZ, J.L., Introducción al Derecho Administrativo, Tecnos, Madrid, 1986, págs. 94-97. 
3. La «mano invisible» de la carrera administrativa - su dimensión institucional - no puede olvidar que sus frutos son el resultado de la iniciativa del funcionario. Esto explica que, tradicionalmente, la normativa haya configurado la carrera profesional y la promoción interna como un derecho del funcionario. Los funcionarios de carrera - dice el art. 16.1 EBEP - tendrán derecho a la promoción profesional.

En este sentido, la carrera profesional ha de ofrecer un conjunto ordenado de oportunidades de ascenso y expectativas de progreso profesional conforme a los principios de igualdad, mérito y capacidad (art. 16.2 EBEP). A estos efectos, las Administraciones Públicas promoverán la actualización y perfeccionamiento de la cualificación profesional de sus funcionarios de carrera (art. 16.2, párrafo $\left.2 .^{\circ}, \mathrm{EBEP}\right)$.

\section{DIFICULTADES Y SOLUCIONES A LA MEDIDA EN EL ÁMBITO LOCAL}

4. El desarrollo de la carrera profesional presenta no pocas dificultades en el ámbito de la Administración local, que - en tantos aspectos - sigue siendo la Cenicienta de nuestras Administraciones públicas.

Hay que tener en cuenta que la mayor parte de nuestros municipios disponen de una estructura administrativa microscópica, que no permite desarrollar una carrera profesional vinculada al desempeño de puestos de trabajo de una creciente cualificación. En mi tierra, por ejemplo, abundan los municipios que solo tienen dos funcionarios. Sólo en las grandes ciudades, el funcionario puede aspirar a subir peldaños en la estructura administrativa. Ello no solo limita el horizonte profesional del funcionario local, sino que puede incidir en la profesionalidad y calidad del empleo público local, e incluso - en algún caso- en su independencia ${ }^{6}$. De ahí que - como a continuación vamos a avanzar- la carrera administrativa local pueda requerir una medicina propia.

5. En concreto, en el ámbito local, la promoción profesional solo puede descansar sobre dos pilares: (i) una adecuada regulación de la llamada carrera horizontal; (ii) la potenciación de la movilidad interadministrativa, sobre todo, basada en cuerpos con habilitación nacional o autonómica (M. LÓPEZ-MUÑIZ).

En esta línea, SÁNCHEZ MORÓN destaca que «sería conveniente, entre otras cosas, recuperar una concepción de conjunto de la función pública local (como existe en Francia, por ejemplo) y facilitar la movilidad, en su caso mediante la creación de escalas de funcionarios con habilitación autonómica, la homogeneización de las pruebas de selección en cada Comunidad Autónoma o, al me-

6 SÁnchez Morón, M., Derecho de la Función Pública, 5. a edic., Tecnos, 2008, pág. 77. 
nos, la superación de cursos de formación en las respectivas Escuelas de Administración Pública. Aunque algunas medidas se vienen adoptando en este sentido (por ejemplo, en las leyes autonómicas de coordinación de Policías Locales), la defensa a ultranza de la autonomía local —es decir, de sus parcelas de poder - por los miembros de las Corporaciones Locales y sus asociaciones representativas hace difícil que se avance en esta dirección» ${ }^{7}$.

6. En el nuevo marco normativo, la potenciación de la carrera administrativa en el ámbito local, sobre todo, es responsabilidad de las CCAA. En esta materia, corresponde al Estado establecer las normas básicas de la carrera administrativa, especialmente, en lo que se refiere a la promoción de los funcionarios a niveles y grupos superiores (art. 90.2, párrafo $2 .^{\circ}, \mathrm{LrBRL}$ ). Sin embargo, el EBEP - aunque aparentemente no renuncia a regular esta materia - en muchos aspectos, lo hace en términos puramente indicativos, lo que - de hecho - supone inhibirse del ejercicio de su competencia. En estas condiciones la normativa básica está tan ausente como el Sr. Godot de S. Beckett ${ }^{8}$. Con el Estatuto en la mano, la fragmentación del modelo de carrera administrativa es inevitable. Se ha dicho incluso que «la finalidad primordial perseguida con la reforma es mermar las competencias básicas del Estado en materia de función pública a favor de las Comunidades Autónomas y sincronizarse con el proceso de profunda descentralización que, en buena parte al margen de la Constitución, protagonizan los Estatutos de Autonomía de corte confederal recientemente aprobados» ${ }^{9}$.

En resumen, en este marco, serán las Leyes de Función Pública que desarrollen el EBEP las que definirán el modelo de carrera administrativa que se va a aplicar en cada ámbito en su territorio (art. 16.3 EBEP). Así, la carrera horizontal es una posibilidad que ofrece el EBEP, cuya asunción dependerá de la voluntad autonómica, que - en su caso - habrá de regular y concretar el modelo. Por lo mismo, la eventual regulación de cuerpos de habilitación autonómica - a imagen y semejanza de los de habilitación nacional-, correspondería a las CCAA, con respeto a la autonomía local. De hecho, el capítulo II del Título III EBEP - relativo a la carrera profesional y a la promoción interna - no entrará en vigor hasta que no sea desarrollado por las leyes de la función pública de las CCAA (Disposición final 4. $\left.{ }^{\mathrm{a}} \cdot 2 \mathrm{EBEP}\right)^{10}$.

7. Así las cosas — entendida en sentido amplio - , la carrera administrativa se articula en torno a dos grandes ejes:

\footnotetext{
7 SÁnCHEZ Morón, M., Derecho..., 5. ${ }^{\mathrm{a}}$ edic., cit., pág. 77.

8 Martín Rebollo, L., El Estatuto del Empleado Público: un Godot que no ha llegado, RAP, 174, 2007, págs. 141-142.

9 Parada VÁzQueZ, R., Derecho..., vol. II, 20. a edic., cit., pág. 406.

10 Embid Irujo, A., Incidencia del Estatuto Básico del Empleado Público en la normativa de las Comunidades Autónomas, REDA, núm. 137, págs. 11 y ss.
} 
1. Carrera profesional dentro de la misma Administración, que incluye: (i) la carrera vertical; (ii) la carrera horizontal; (iii) y la promoción interna.

2. Movilidad interadministrativa, que incluye: (i) la potenciación y/o creación de cuerpos de habilitación supralocal; (ii) la facilitación de la movilidad voluntaria de los funcionarios.

\section{CARRERA PROFESIONAL DENTRO DE LA MISMA ADMINISTRACIÓN}

8. El EBEP no establece un modelo cerrado de carrera profesional, sino que encomienda a las Leyes de desarrollo la regulación del modelo aplicable en cada ámbito, que podrá consistir, entre otras, en la aplicación aislada o simultánea de alguna o algunas de las modalidades contempladas en el art. 16.3 EBEP.

Además, no se trata de modelos excluyentes, sino que las distintas alternativas de promoción profesional pueden aplicarse conjuntamente. De ahí que la legislación prevea que los funcionarios puedan progresar simultáneamente en las modalidades de carrera horizontal y vertical cuando la Administración correspondiente las haya implantado en un mismo ámbito (art. 16.4 EBEP). Como es obvio, estas modalidades de carrera administrativa tampoco excluyen la promoción interna.

Con todo - como ya hemos advertido-, en esta materia el EBEP no es directamente aplicable, sino que está necesitado de una regulación de desarrollo. Mientras ésta no se produzca, se aplicarán las disposiciones vigentes en materia de carrera profesional, promoción, régimen retributivo y provisión de puestos de trabajo (Disposición Final 3. a 2 EBEP).

9. Por otra parte - con carácter previo - , debe recordarse que la provisión de puestos de trabajo es también acceso a un cargo o función pública, por lo que - de acuerdo con el art. 23.2 $\mathrm{CE}^{11}$ - ha de hacerse en condiciones de igualdad.

\section{A. Carrera vertical: promoción profesional a través de la provisión de puestos de trabajo}

10. La Ley 30/1984, de 4.8, de Medidas de Reforma de la Función Pública, hizo descansar el modelo de función pública sobre el puesto de trabajo, en detrimento de los Cuerpos y categorías profesionales. La consecuencia es que la ca-

11 Así lo reconoce una jurisprudencia constante: STC 75/1983, STC 15/1988, STC 47/1989, STC 192/1991, STC 293/1993. 
rrera administrativa del funcionario consiste en la sucesiva ocupación de puestos de trabajo de un nivel jerárquico superior. Como corrección del sistema, el desempeño del puesto de trabajo durante dos años consecutivos - o tres con interrupción - permite al funcionario consolidar el grado personal ${ }^{12}$. La reforma de la Ley 23/1988, en parte, vino a descafeinar el sistema, ya que el grado personal no garantiza el desempeño de un puesto de trabajo, que antes - necesariamente- debía estar situado dos niveles por encima o por debajo de su nivel consolidado. Los funcionarios podrán ocupar cualquier puesto de trabajo dentro del intervalo que corresponda a su puesto o escala. No obstante, el grado personal consolida la carrera a efectos retributivos: como mínimo, el funcionario tendrá derecho a obtener el complemento de destino que corresponda a su grado personal. A ello se añade, el carácter honorífico que siempre representa el haber consolidado uno u otro grado personal. En definitiva, en estos términos, el sistema se basa en una combinación entre el puesto de trabajo y el grado personal.

11. El EBEP permite la continuidad de este modelo, que da lugar a la carrera vertical del funcionario. Esta consiste en el ascenso en la estructura de puestos de trabajo [art. 16.3.b) EBEP], lo que — como regla - se producirá a través de dos procedimientos: concurso y libre designación con convocatoria pública.

A este respecto, el Estatuto no introduce novedades destacables respecto de la regulación anterior. La carrera profesional de los funcionarios de carrera se iniciará en el grado, nivel, categoría, escalón y otros conceptos análogos correspondientes a la plaza inicialmente asignada al funcionario tras la superación del correspondiente proceso selectivo, que tendrán la consideración de mínimos (Disposición Adicional 10. ${ }^{a}$ EBEP). A partir de aquellos, se producirán los ascensos que procedan según la modalidad de carrera aplicable en cada ámbito.

\section{B. Carrera horizontal: promoción profesional sin cambiar de puesto de trabajo}

12. Entre las novedades del EBEP está la llamada carrera horizontal, que consiste en la progresión de grado, categoría, escalón u otros conceptos análogos, sin necesidad de cambiar de puesto de trabajo y de conformidad con lo establecido en los arts. 17.b) y 20.3 EBEP [art. 16.3.a) EBEP].

El informe de la Comisión de Expertos que sirvió de base para la redacción del proyecto de EBEP razonó que el modelo de carrera profesional introducido

\footnotetext{
12 «La inexistencia de una carrera administrativa fue uno de los peores efectos del sistema de función pública de 1963-1964. Suprimidas las viejas categorías de la legislación de Bravo Murillo, inútiles desde luego en la época, no se sustituyeron por ningún sistema objetivo de promoción. Salvo el pequeño aumento de retribución por años de servicio (trienios), no había más medio de promoción que el acceso a puestos de jefatura, lo que provocó la inflación orgánica... La Ley de Medidas sale al paso de esta situación creando los grados personales de los funcionarios, que se corresponden parcialmente con los puestos de trabajo». BAENA Del AlCAZAr, M., Curso de Ciencia de la Administración, vol. I, 3. a edic., Tecnos, Madrid, 1996, pág. 470.
} 
por la Ley 30/1984 conduce a una excesiva movilidad voluntaria del personal, ya que - si quiere progresar - «el funcionario de carrera se ve obligado a cambiar de puesto de trabajo». Solo el cambio a puestos de trabajo de mayor nivel permite consolidar un mayor grado personal. Se ha dicho que esto tiene efectos disfuncionales: (i) el funcionario debe abandonar la tarea que está desarrollando para ocuparse de nuevos ámbitos, en los que tendrá que cualificarse; (ii) las Administraciones públicas pueden verse obligadas a crear artificialmente nuevos puestos de trabajo, sencillamente, para mejorar su complementos $\mathrm{y}$, con ello, poder retener a sus funcionarios.

13. La regulación de la carrera horizontal no es un imperativo, sino una posibilidad que ofrece el EBEP, que puede o no ser acogida por las Leyes de Función Pública que se dicten en su desarrollo ${ }^{13}$. Además, el legislador contará con plena libertad para configurar esta modalidad de carrera administrativa, ya que - a estos efectos - el art. 17 EBEP solo ofrece algunas reglas que podrán ser aplicadas. En concreto, el Estatuto - en términos impropiamente imperativos - permite:

- Articular un sistema de grados, categorías o escalones de ascenso, fijándose la remuneración a cada uno de ellos [art. 17.a) EBEP]. Con carácter general, los ascensos deben ser consecutivos, salvo en los supuestos excepcionales en los que se prevea otra posibilidad.

- Como criterios para la promoción profesional se ofrece la valoración de la calidad de los trabajos realizados, los conocimientos adquiridos y el resultado de la evaluación del desempeño [art. 17.b) EBEP]. Asimismo, podrán incluirse otros méritos y aptitudes por razón de la especificidad de la función desarrollada y la experiencia adquirida. Entre los criterios a valorar no se incluye la antigüedad - que figuraba en el Proyecto de Ley -, lo que no impide que pueda ser tomado en cuenta por la legislación autonómica.

En definitiva, el modelo está por armar: «la legislación de desarrollo debe configurar en concreto los criterios de ascenso e inclusive si existe o no un cupo o número máximo de ascensos posibles en cada momento, lo que implica una selección de los mejores, o bien sancionar el derecho a ascender de categoría de todo aquel funcionario que, en un período determinado, reúna los méritos y cualidades suficientes. Del mayor o menor automatismo de la progresión en la carrera dependerá en la práctica que la reforma alcance o no sus objetivos. De ahí que la eventual configuración de modelos de ascenso sobre la base de una mera acreditación de años de servicio o de méritos universales y de fácil obtención... supondría en realidad un fraude de ley» ${ }^{14}$. Con todo - si la antigüedad

13 SÁnchez Morón, M., Derecho..., 5. a edic., cit., pág. 154.

14 SÁnchez Morón, M., Derecho..., 5. a edic., cit., pág. 155. 
no es el criterio - , habrá que asegurar que hay suficientes elementos objetivos de valoración, que eviten que la promoción profesional degenere en el subjetivismo o en la arbitrariedad.

14. Este nuevo modelo ha cosechado severas críticas, entre las que destacan las de PARADA, que se refiere a él como la «carrera de los inmóviles». Sin embargo, en el ámbito local, la carrera horizontal permite hacer de la necesidad virtud. Como hemos advertido, la mayor parte de las entidades locales no disponen una relación suficiente de puestos de trabajo que permita desarrollar una carrera vertical. De ahí que - si se quiere mantener el estímulo - deba ofrecerse un sistema que permita la progresiva cualificación profesional de un funcionario anclado a su puesto de trabajo.

15. Con todo, una vez más, hay que recordar que la carrera horizontal no será efectiva hasta que - en su caso - sea regulada por las leyes de desarrollo del EBEP.

\section{Promoción interna}

16. La promoción interna ${ }^{15}$ es un trampolín que permite al funcionario dar un salto cualitativo en su carrera profesional, pasando de un grupo o subgrupo y/o cuerpo o escala a otro. A estos efectos, el EBEP contempla dos modalidades de promoción interna:

1. Promoción interna vertical, que consiste en el ascenso desde un cuerpo o escala de un Subgrupo, o Grupo de clasificación profesional en el supuesto de que éste no tenga Subgrupo, a otro superior [art. 16.3.c) EBEP].

2. Promoción interna horizontal, que consiste en el acceso a cuerpos o escalas del mismo Subgrupo profesional [art. 16.3.d) EBEP]. La Ley 30/1984 condiciona esta promoción a que ambos cuerpos tengan encomendadas funciones sustancialmente coincidentes o análogas en su contenido profesional y en su nivel técnico.

17. La promoción interna constituye un cualificado elemento de impulso a la carrera profesional de los servidores públicos. De hecho, la Ley obliga a las Administraciones públicas a adoptar medidas que incentiven la participación de su personal en los procesos selectivos de promoción interna y para la progresión en la carrera profesional (art. 18.4 EBEP). Con todo, este objetivo debe necesariamente conjugarse con los principios de igualdad, capacidad y mérito en el acceso a la función pública. La reserva de plazas a la promoción interna

15 Alegre Ávila, J.M., La promoción interna de los funcionarios públicos, RAP, núm. 113, 1987, págs. 217 y ss. 
va en detrimento de los ciudadanos que se presentan por el turno libre. En el ámbito local - aunque se parte del principio general de que las convocatorias serán siempre libres - se permite una generosa reserva para promoción interna de hasta el 50\% de las plazas convocadas (art. 134.1 TrRL).

18. La promoción interna de los funcionarios de carrera se realizará mediante procesos selectivos que garanticen el cumplimiento de los principios constitucionales de igualdad, mérito y capacidad, así como los contemplados en el art. 55.2 EBEP (art. 18.1 EBEP).

Los funcionarios deberán poseer los requisitos exigidos para el ingreso, tener una antigüedad de, al menos, dos años de servicio activo en el inferior Subgrupo, o Grupo de clasificación profesional, en el supuesto de que éste no tenga Subgrupo y superar las correspondientes pruebas selectivas (art. 18.2 EBEP).

Las Leyes de Función Pública que se dicten en desarrollo del EBEP articularán los sistemas para realizar la promoción interna, así como también podrán determinar los cuerpos y escalas a los que podrán acceder los funcionarios de carrera pertenecientes a otros de su mismo Subgrupo (art. 18.3 EBEP).

Asimismo, las Leyes de Función Pública que se dicten en desarrollo del presente Estatuto podrán determinar los cuerpos y escalas a los que podrán acceder los funcionarios de carrera pertenecientes a otros de su mismo Subgrupo.

19. El personal laboral también tendrá derecho a la promoción profesional (art. 19.1 EBEP). La carrera profesional y la promoción del personal laboral se hará efectiva a través de los procedimientos previstos en el Estatuto de los Trabajadores o en los convenios colectivos (art. 19.2 EBEP).

\section{MOVILIDAD INTERADMINISTRATIVA}

20. Como venimos advirtiendo, la mayor parte de los municipios tienen unas estructuras administrativas elementales, lo que limita la posibilidad de desarrollar la carrera administrativa en el seno de la propia Administración. De ahí que la movilidad interadministrativa pueda representar una oportunidad para que el personal al servicio de las entidades locales pueda promocionarse profesionalmente.

En realidad, lo que llamamos movilidad interadministrativa agrupa dos fenómenos distintos: (i) El sistema normal de provisión de puestos de trabajo reservados a funcionarios locales con habilitación estatal (o en el futuro, autonó- 
mica); (ii) La movilidad voluntaria de funcionarios, que constituye una vía de flexibilización del sistema.

\section{A. Provisión de puestos de trabajo por funcionarios con habilitación estatal o autonómica}

21. La legislación local, tradicionalmente, ha reservado determinadas funciones públicas a los funcionarios con habilitación de carácter nacional. Por su configuración misma, este cuerpo favorece la movilidad interadministrativa, ya que - aunque en cada momento están al servicio de una concreta entidad local - su habilitación nacional les permite concurrir a los concursos de provisión de puestos de trabajo convocados por cualquier otra entidad local. Más aún, el éxito de este modelo permite valorar la conveniencia de su generalización a nivel autonómico, lo que garantizaría la movilidad interadministrativa - cuanto menos, en el territorio de la respectiva $\mathrm{CA}$ - de los restantes funcionarios (M. LÓPEZ-MUÑIZ).

22. El EBEP ha introducido cambios sustanciales ${ }^{16}$ en el régimen básico de los ahora llamados funcionarios locales con habilitación estatal ${ }^{17}$. La normativa estatal sigue regulando aspectos esenciales de su régimen jurídico:

- Son funciones públicas necesarias en todas las Corporaciones locales, reservadas a funcionarios con habilitación de carácter estatal (Disposición Adicional 2. ${ }^{a}$.1.1.2 EBEP): (i) la de secretaría, comprensiva de la fe pública y el asesoramiento legal preceptivo; (ii) el control y la fiscalización interna de la gestión económico-financiera y presupuestaria, y la contabilidad, tesorería y recaudación.

- La escala de funcionarios con habilitación de carácter estatal se subdivide en las siguientes subescalas: (i) Secretaría; (ii) Intervencióntesorería; (iii) Secretaría-intervención (Disposición Adicional 2. ${ }^{\text {a }} 2$ EBEP). Los funcionarios de las subescalas de secretaría e intervención-tesorería estarán integrados en una de estas dos categorías: entrada o superior.

- Su nota sustantiva permanece, ya que su habilitación les permite participar en los concursos de méritos convocados para la provisión de los puestos de trabajo reservados a estos funcionarios en las plantillas de las entidades locales (Disposición Adicional 2. ${ }^{a} .4$, párrafo 4. ${ }^{\circ}, \mathrm{EBEP}$ ).

\footnotetext{
16 Las disposiciones relativas a la selección y formación de los funcionarios locales con habilitación nacional, reguladas en los arts. 98-99 LrBRL, han sido derogadas por la disposición derogatoria del EBEP.

17 De manera transitoria - en tanto no se aprueben las normas de desarrollo de la Disposición Adicional 2. ${ }^{\text {a }}$ - , continuarán en vigor las disposiciones que regulan la Escala de Funcionarios de Administración Local con habilitación de carácter nacional (Disposición Transitoria 7. ${ }^{\text {a EBEP). }}$
} 
No obstante, el EBEP traslada a las CCAA las funciones principales en relación con este colectivo, como son la selección, nombramiento, provisión de puestos de trabajo y régimen disciplinario:

- La creación, clasificación y supresión de puestos de trabajo reservados a funcionarios con habilitación de carácter estatal corresponde a cada CA, de acuerdo con los criterios básicos que se establezcan por Ley (Disposición Adicional 2. ${ }^{a} .3$ EBEP).

- Corresponde a las CCAA la convocatoria de la oferta de empleo para cubrir las vacantes existentes (Disposición Adicional 2. a.4 EBEP).

- La selección corresponde ahora también a las CCAA, conforme a los títulos académicos requeridos y programas mínimos que apruebe el MAP. Las CCAA publicarán las convocatorias de las pruebas selectivas en sus Diarios Oficiales y las remitirán al MAP para su publicación en el $B O E$. Celebradas las pruebas, las CCAA remitirán al MAP la relación de funcionarios que «nombren», con el fin de que éste acredite la correspondiente habilitación estatal obtenida y proceda a su inscripción en el registro de funcionarios con habilitación de carácter estatal.

- El concurso será el sistema normal de provisión de puestos de trabajo, en el que habrán de tenerse en cuenta: (i) los méritos generales; (ii) el conocimiento de las especialidades de la organización territorial de cada CA y de su Derecho; (iii) el conocimiento de la lengua oficial; (iv) y los méritos específicos directamente relacionados con las características del puesto (Disposición Adicional 2. ${ }^{\mathrm{a}}$.5.5.1 EBEP).

- Existirán dos concursos anuales: el ordinario y el unitario. (i) Las CCAA regularán las bases comunes del concurso ordinario - incluido el porcentaje de puntuación que corresponda a cada uno de los méritos - , que tendrá un ámbito territorial autonómico. La convocatoria y resolución del concurso corresponde a las entidades locales. (ii) De manera supletoria, el MAP efectuará la convocatoria anual de un concurso unitario - de ámbito estatal - de los puestos de trabajo vacantes.

- Excepcionalmente - en los municipios de gran población (art. 121 LrBRL), así como las Diputaciones Provinciales, Cabildos y Consejos Insulares - , podrá utilizarse el sistema de libre designación respecto de los puestos que se determinen en las RPT (Disposición Adicional 2. ${ }^{\mathrm{a}}$.5.5.12 EBEP).

- Las CCAA efectuarán, de acuerdo con su normativa, los nombramientos provisionales de funcionarios con habilitación de carácter estatal, así como las comisiones de servicios, acumulaciones, nombramientos de personal interino y de personal accidental (Disposición Adicional 2. ${ }^{a}$ 5.5.3 EBEP). 
- El régimen disciplinario aplicable a los funcionarios con habilitación de carácter estatal se regulará por lo dispuesto por cada CA, correspondiendo al Ministerio de Administraciones Públicas la resolución de los expedientes disciplinarios en los que el funcionario se encuentre destinado en una Comunidad distinta a aquélla en la que se le incoó el expediente (Disposición Adicional 2. $\left.{ }^{\mathrm{a}} 6 \mathrm{EBEP}\right)$.

- Los funcionarios con habilitación de carácter estatal se regirán por los sistemas de acceso, carrera, provisión de puestos y agrupación de funcionarios aplicables en su correspondiente CA, respetando lo establecido en el EBEP (Disposición Adicional 2. ${ }^{\mathrm{a}}$.7 EBEP).

El excesivo protagonismo que van a asumir las CCAA en relación con estos funcionarios puede acabar encerrándolos en los linderos regionales. A ello se unen otras prácticas, que han contribuido a debilitar al colectivo. Así, la libre designación como procedimiento de provisión - que fue ya introducida por la Ley 10/1993 y avalada por la STC 235/2000 - «resulta fuertemente contradictorio con las funciones de control y fe pública que realizan estos funcionarios y con las estrictas garantías de imparcialidad que es preciso acordarles» ${ }^{18}$. No pueden tampoco silenciarse los abusos a que ha dado lugar la posibilidad de nombrar a estos funcionarios con carácter interino, que introdujo el art. 64 de la Ley 42/1994. «Todas estas reformas de unos cuerpos que nacieron para controlar desde dentro la legalidad de la actuación de los electos locales no benefician precisamente el ejercicio independiente, responsable y eficaz de esta labor» ${ }^{19}$. Como puede verse, los vientos soplan, justo, en la dirección contraria a la conveniente.

23. A diferencia de lo que sucede con los funcionarios con habilitación nacional, la movilidad interadministrativa - en principio - no está garantizada respecto de los restantes funcionarios locales. Hay que tener en cuenta a este respecto que la selección y provisión de puestos de trabajo corresponde a cada entidad local:

- Es de competencia de cada Corporación local la selección de los funcionarios que no tengan habilitación de carácter estatal (art. 100.1 LrBRL), dentro de las reglas básicas establecidas por el Estado (art. 100.2 LrBRL $)^{20}$.

- Estos funcionarios se integrarán en las escalas, subescalas, clases y categorías de cada Corporación (art. 131.1 TrRL). Las subescalas, clases y

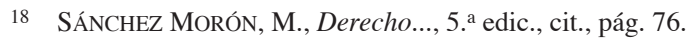

19 SÁnChez Morón, M., Derecho..., 5. a edic., cit., págs. 76-77.

20 De acuerdo con el art. 100.2 LrBRL, corresponde a la Administración del Estado establecer: las reglas básicas y los programas mínimos a que debe ajustarse el procedimiento de selección y formación de tales funcionarios; los títulos académicos requeridos para tomar parte en las pruebas selectivas, así como los diplomas expedidos por el INAP o por los Institutos o Escuelas de funcionarios establecidos por las CCAA, complementarios de los títulos académicos que puedan exigirse.
} 
categorías quedaran agrupadas conforme a la legislación básica del Estado en los grupos que ésta determine, de acuerdo con la titulación exigida para su ingreso (art. 131.2 TrRL).

- Los puestos de trabajo vacantes que deban ser cubiertos por los funcionarios a que se refiere el artículo anterior se proveerán en convocatoria pública por los procedimientos de concurso de méritos o de libre designación, de acuerdo con las normas que regulen estos procedimientos en todas las Administraciones públicas (art. 101, párrafo 1.․ LrBrL). En dichas convocatorias de provisión de puestos de trabajo, además de la participación de los funcionarios propios de la entidad convocante, podrán participar los funcionarios que pertenezcan a cualquiera de las Administraciones públicas, quedando en este caso supeditada la participación a lo que al respecto establezcan las relaciones de puestos de trabajo (art. 101, párrafo $2 .^{\circ}, \mathrm{LrBrL}$ ).

24. En la práctica, estas características encadenan al funcionario a su respectiva Administración, haciendo muy difícil la movilidad. Desde la perspectiva del interés general, esto puede tener también dos consecuencias negativas: (i) una menor cualificación del personal (cuanto mayor sea el ámbito territorial, mayor será también la posibilidad de que un número más amplio de interesados se sientan atraídos por los procesos selectivos); (ii) eventualmente, mayor dificultad en el desempeño de la función en las debidas condiciones de objetividad e imparcialidad (la cercanía de los intereses políticos pueden llegar a ejercer una presión -más o menos difusa - , pero no pequeña sobre el funcionario).

25. En cambio, estos males podrían verse superados, si se «integrase la función pública local que no requiere hoy habilitación nacional, en un sistema de carácter, al menos, autonómico, de modo que se constituyera una carrera administrativa que aunara a todo el personal funcionario de todas las Administraciones locales del territorio de cada Comunidad Autónoma, o que incluso la integrase con la propia del personal de ésta. Se trataría, en suma, de garantizar un sistema unificado de selección para el ingreso en los Cuerpos y Escalas de funcionarios así como de su formación... La carrera sería única, pero los funcionarios locales podrían ocupar puestos en cualquiera de las Administraciones locales del territorio autonómico... Obviamente cada Administración mantendría sus facultades en orden a los procedimientos de provisión de sus puestos de trabajo y concesión de situaciones administrativas a los funcionarios destinados en ellas, así como en orden a su retribución y sanción, dentro de un estatuto común que habría de concretarse por ley autonómica. Y como decimos, esa unificación podría incluso hacerse con los Cuerpos y Escalas de la misma Comunidad Autónoma» (M. LÓPEZ-MUÑIZ).

Este modelo encontraría acomodo en el esquema de mínimos que diseña el EBEL, una vez que sea desarrollado por las correspondientes leyes autonómicas. No suscitaría tampoco problemas desde la perspectiva del necesario respe- 
to a la autonomía local, como no los plantea la existencia de los actuales funcionarios locales de habilitación nacional.

26. A este respecto, hay que tener en cuenta que algunas normas contemplan ya la posibilidad de que los funcionarios locales sean seleccionados por la CA. En este sentido, el Decreto legislativo de Valencia, de 24.10.1995, por el que se aprueba el Texto refundido de la Ley de la Función Pública, prevé que:

- Las Corporaciones Locales - por acuerdo del Pleno-, puedan acogerse a los procedimientos de acceso autonómicos, incorporando su oferta pública de empleo a la de la Administración regional, de modo que su personal funcionario sea seleccionado por ésta (art. 10.1).

- Una vez seleccionado, corresponderá a la Corporación Local su nombramiento (art. 10.2).

- El funcionario seleccionado por este procedimiento «podrá participar en los concursos de provisión de puestos que convoque la Generalitat Valenciana y demás entidades locales que se hubieran acogido al sistema previsto en el presente artículo, en las mismas condiciones y derechos que el personal de la Generalitat Valenciana» (art. 10.3).

- Por lo mismo, los funcionarios de la CA podrán acceder a las convocatorias de provisión de las entidades locales que se hubieran acogido al sistema de selección mencionado, adquiriendo la condición de funcionario local, en igualdad de condiciones y derechos que los demás (art. 10.4).

- En este caso, los funcionarios se someterán al régimen estatutario y legislación en materia de función pública que sea aplicable a la Administración en la que presten sus servicios, pero conservarán la condición de funcionario de su Administración de origen, en la situación de servicios en otras Administraciones Públicas, manteniendo todos sus derechos como si se hallasen en servicio activo, salvo la reserva del puesto de trabajo y lugar de destino (art. 36.4). No obstante, la sanción de separación del servicio sólo podrá ser acordada por el Gobierno valenciano u otro órgano competente en materia de personal de su Administración de origen, previa audiencia de la persona interesada.

27. En definitiva, la homogeneización de los cuerpos y escalas, así como el reconocimiento a las CCAA de facultades para la selección de los funcionarios, en nada, merma la capacidad de autogobierno de las Corporaciones locales. Al contrario - como venimos insistiendo-, introduce un elemento de racionalización del sistema, que solo puede contribuir a que éstas cuenten con un personal más cualificado. Por otra parte — como se ha apuntado-, correspondería a las entidades locales, no solo la provisión de puestos de trabajo, sino 
también el ejercicio de las funciones ejecutivas necesarias para ordenar la relación de servicios del funcionario.

\section{B. Flexibilización del sistema: movilidad voluntaria de los restantes funcionarios locales}

28. La movilidad voluntaria de los funcionarios entre las distintas Administraciones públicas constituye una vía de flexibilización del sistema, que -limitadamente - puede servir también a los fines de la carrera administrativa.

29. Como es normal, los concursos de provisión de puestos de trabajo se dirigen a los funcionarios de la Administración convocante. No obstante, la legislación más reciente ha favorecido también la movilidad interadministrativa. En este sentido, el art. 17.1 de la Ley 30/1984 - con la finalidad de lograr una mejor utilización de los recursos humanos - contemplaba la posibilidad de que los puestos de trabajo de la Administración del Estado y de las CCAA pudieran ser cubiertos por funcionarios que pertenecieran a cualquiera de estas Administraciones públicas, siempre que así lo establecieran las RPT. Esta misma regla se extendía después a los funcionarios locales, a los que se habría también la movilidad a otras Corporaciones locales, a las CCAA o a la Administración del Estado, en puestos relacionados con las funciones que les competen en materia de entidades locales (art. 17.2). Finalmente, el art. 101, párrafo 2. ${ }^{\circ}$, LrBRL prevé que, en las convocatorias de provisión de puestos de trabajo - además de los funcionarios propios de la entidad convocante-, podrán participar también los funcionarios que pertenezcan a cualquiera de las Administraciones públicas, quedando en este caso supeditada la participación a lo que al respecto establezcan las relaciones de puestos de trabajo.

30. En la actualidad, esta regulación ha sido sustituida por el art. 84 EBEP, que contempla la movilidad voluntaria entre Administraciones públicas -Estado, CCAA y entidades locales -, en los siguientes términos:

1. La movilidad interadministrativa no sirve primariamente a la carrera administrativa, sino a la racionalidad en la gestión pública. Esto explica que no se configure como un derecho de los funcionarios, ya que su finalidad es «lograr un mejor aprovechamiento de los recursos humanos, que garantice la eficacia del servicio que se preste a los ciudadanos» (art. 84.1 EBEP) (MARTín REBOLLO). Con todo - como hemos avanzado-, limitadamente, esta vía puede servir también para flexibilizar la carrera profesional del funcionario.

2. Su articulación puede requerir el establecimiento de instrumentos de colaboración entre las distintas Administraciones, preferentemente mediante convenio de Conferencia Sectorial (art. 84.1 EBEP). 
3. La movilidad interadministrativa puede requerir la previa homologación de los métodos de los sistemas de acceso y carrera de los funcionarios. A este respecto, la Conferencia Sectorial de Administración Pública podrá aprobar los criterios generales a tener en cuenta para llevar a cabo las homologaciones necesarias para hacer posible la movilidad (art. 84.2 EBEP).

4. Los funcionarios de carrera que obtengan destino en otra Administración Pública a través de los procedimientos de movilidad quedarán respecto de su Administración de origen en la situación administrativa de servicio en otras Administraciones Públicas (art. 84.3 EBEP). En este sentido, la normativa local contempla como situación en que pueden encontrarse los funcionarios de carrera de la Administración local la de servicio en CCAA [art. 140.1.b) TrRL].

5. En los supuestos de cese o supresión del puesto de trabajo, permanecerán en la Administración de destino, que deberá asignarles un puesto de trabajo conforme a los sistemas de carrera y provisión vigentes en dicha Administración (art. 84.3, párrafo 2. $\left.{ }^{\circ}, \mathrm{EBEP}\right)$.

31. Con todo, en la práctica, la movilidad interadministrativa es más bien escasa, debido no solo a las diferentes condiciones de acceso y exigencias de la carrera en las distintas Administraciones públicas, sino también a la resistencia de los funcionarios (y de sus organizaciones representativas) a aceptar concursos abiertos ${ }^{21}$. Por otra parte, el creciente particularismo en que está derivando la dinámica autonómica no se cansa de sembrar nuevos obstáculos a la movilidad interadministrativa. A este respecto, es sintomático el art. 42.4 de la Ley de Galicia 4/1988, de 26.5, de la Función Pública, que prohíbe que el personal procedente de otras Administraciones públicas en servicio activo supere el 5\% de los efectivos totales de la Administración regional ${ }^{22}$.

21 SÁnchez Morón, M., Derecho..., 5. a edic., cit., pág. 161.

22 En su redacción de la Ley 13/2007, de 27.7. 